\title{
DESIGN OF A MOBILE E-LEARNING FORECASTING SYSTEM BASED ON A CASE STUDY USING MULTIPLE INTELLIGENCE ANALYSIS
}

\author{
Thongchai Kaewkiriya \\ Thai-Nichi Institute of Technology \\ 1771/1 Pattanakarn Rd., Suanluang, Bangkok, Thailand \\ thongchai@tni.ac.th
}

\begin{abstract}
This research aimed to design a mobile e-Learning forecasting system based on case studies using Multiple Intelligence analysis. The framework is divided into six modules. The first module describes a Patterns-based module. The second module describes the student Mapping module. The third module presents the Forecasting module. The fourth module presents the Learning portal module. The fifth module explains the Adaptive module. The last module presents the learning content based on the case study modules. In addition this paper introduces an example of an operational framework. The evaluation is comprised of two sections. The first section evaluates student achievement. The second section evaluates student prediction precision. The results of the first evaluation showed that students who studied via the mobile e-Learning forecasting system are more successful than students who studied via the normal e-Learning system with significance at 0.05 (Group 1, $t=7.577, p<0.05$; Group 2, $t=3.684, p<$ 0.05 ; Group 3, $t=15.190, p<0.05)$. For the second section, the results considered the prediction precision percentage. We compared three algorithms: 1) J48 algorithm, 2) ID3 algorithm, and the 3) Naïve Bayes algorithm. The $\mathrm{J} 48$ algorithm had the highest value at $88.286 \%$.
\end{abstract}

Keywords: E-Learning, Adaptive, Multiple Intelligence, Data Mining, Recommendation system 


\section{INTRODUCTION}

Current learning and instructional systems are rapidly developing, and include methods such as e-Learning ${ }^{1}$, learning and teaching via VDO conference systems ${ }^{2}$, learning and teaching via satellite ${ }^{2}$, etc. Generally, students have different abilities or aptitudes. Therefore, if students are not skilled in a particular field their learning performances will be not be optimal. Past research has looked at styles of learning and teaching that emphasize learner-centered learning ${ }^{3}$. This approach to learning and teaching focuses on the role of students. The instructor is responsible only for providing guidance to the students. The problem is that the learner alone cannot always solve the problem. Because each student has a different ability, students receiving the same lesson may not have the same study performance results.

Research $^{4}$ has looked into learning and teaching by using a project base learning method that focuses on students working on a project as their main task. The learning and instruction derive from the project. A project can be divided into groups according to students and lessons. Research ${ }^{5}$ shows that learning and teaching by using a problem base learning method can be very effective. This learning and teaching focuses on encouraging students to learn by defining the problem and learning how to solve it. This learning and teaching is suitable for students who have analytical skills. There are still, however, some similar drawbacks. When students do not receive lessons based on their individual skills and aptitudes, they may not learn at an optimal pace. Furthermore, students do not necessarily know which skills are best applied to optimize their own learning. Research ${ }^{6}$ has looked into learning and teaching that focuses on learning activities. This type of research will focus on learning activities. The limitation is that students currently do not receive learning content for a case study according to their abilities.

Although learning and teaching using problem-based learning, activity based learning, and student-centered learning are effective, they all have the limitation of students receiving learning content from case studies that might not match their aptitudes. This research presents the design of an adaptive e-learning system based on case studies using Multiple Intelligence (MI) analysis.

\section{RELATED WORK}

Previous research ${ }^{7}$ has introduced the design of an e-Learning system based on students' aptitudes according to MI analysis. There were, however, 
some limitations, including being difficult to identify e-Learning lessons according to Multiple Intelligence analysis. Due to the variety of courses and lessons in many fields, some subjects may not identify content that matches MI analysis. This research presents lessons that can use content from case studies according to MI analysis. Thus, learners can engage with case studies that meet their MI aptitude . $^{8}$.

Presents learning and teaching in a Multiple Intelligence environment. The application of Multiple Intelligence is used in only four areas. The limitation is that there is no evaluation of students during classes when problems occur. In addition, the research proposed by utilizes the application of Multiple Intelligence with hypermedia ${ }^{9}$. Such research has proposed a process that is adjusted to match students, but the learning content is not adapted to students' aptitudes. Also ${ }^{10}$ proposed a model of an online project based on learning systems that advise students. Such research guides students, but does not adjust lessons to meet students' aptitudes and only focuses on project-based learning. In addition, Tangwannawit ${ }^{11,12}$ presented learning activities by using Multiple Intelligence in the environment of e-Learning. Such research focused only on the learning activity and does not offer lessons to match student skills.

Moreover, Herman $\mathrm{Dwi}^{13}$ proposed the design of an adaptive E-Learning system based on student learning styles. The system was adapted by using VARK (Visual-Aural-Read/write-Kinesthetic) and Felder. The limitations included an analysis based on VARK that might not match different styles and abilities of students learning by the VARK model. As well, Panto ${ }^{14}$ presented the design of an adaptive e-Learning system based on the VARK model. This research focused on the learning styles of different students according to an analysis of the VARK model. However, it was also limited by not supporting student aptitudes who differ based on the VARK model.

According to limitations in past studies, this paper proposed a framework for an Adaptive e-Learning recommendation system based on Multiple Intelligence. Each learner will receive lessons in the form of case studies according to their aptitudes from a Multiple Intelligence analysis. This will support the differences between students and can maximize benefits to the students. E-Learning lessons were prepared in three different formats according to Multiple Intelligence. Each student will receive lessons according to their aptitude. There is also a fully automatic guidance system based on the learning styles of individual students. 


\section{BACKGROUND}

\subsection{Multiple Intelligence Theory}

The theory of Multiple Intelligence ${ }^{15,16}$ puts forth that each learner has different aptitudes that can be divided into cognitive aptitudes of nine types: (1) Verbal/Linguistic Intelligence, (2) Logical/Mathematical Intelligence, (3) Musical-Rhythmic Intelligence, (4) Body/Kinesthetic Intelligence, (5) Visual/Spatial Intelligence, (6) Interpersonal Intelligence, (7) Intrapersonal Intelligence, (8) Naturalist Intelligence, and (9) Existential Intelligence. According to the nine types of intelligence, each learner has different dominant intellectual aptitudes. The most important aspect concerns individual progress, which is reflected by improvement of the dominant areas of intelligence In addition, each learner may have more than one dominant area of intelligence. The Multiple Intelligence model is shown in Figure 1.

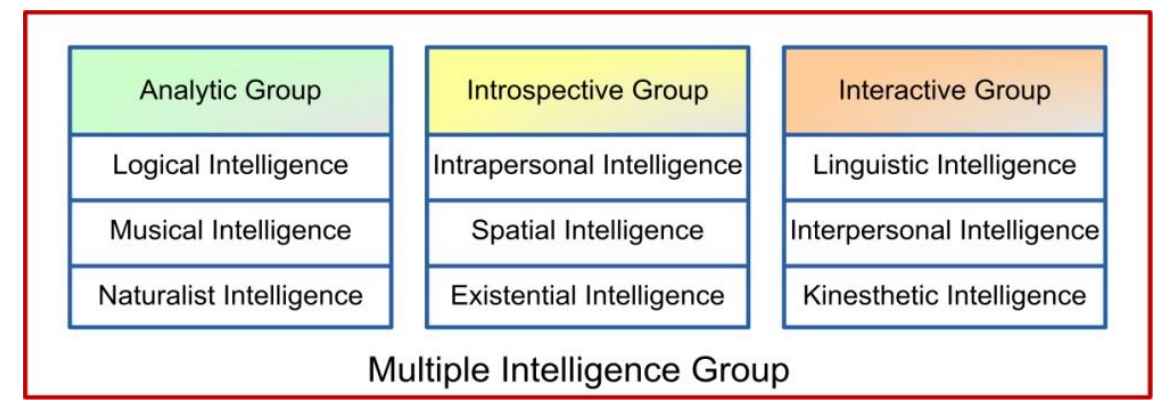

Figure 1. Multiple intelligence model ${ }^{15}$

The Multiple Intelligence theory consists of three groups. 1) The Analytical group focuses on analysis and thinking processes and is divided into three sections: Logical-mathematic intelligence, Musical intelligence, and Naturalist intelligence. 2) The Introspective group focuses on imagination and understanding and is divided into three sections: Intrapersonal intelligence, Spatial intelligence, and Existential intelligence. 3) The Interactive group focuses on communication and interactive and is divided into three sections: Linguistic intelligence, Interpersonal intelligence, and Kinesthetic intelligence.

This research uses the principle of Multiple Intelligence to design a rule base for the e-Learning recommendation system. The design of the rule base is just one of six modules in the framework which is based on the Multiple Intelligence principle (See Fig. 2). 


\section{CONCEPTUAL FRAMEWORK}

Figure 2 shows the framework of the mobile learning guidance system that consists of six modules.

\subsection{Pattern-Based Module}

The Pattern-based module (PBM) analyzes student learning using the theory of MI by creating a Pattern base. The creation of the Pattern base consists of three steps: In the first step, we created a questionnaire that consists of two parts: (1) a Multiple Intelligence exam that we define as the dependent variable; and (2) the learner profile, which is defined as the independent variable. In addition, factors that are affected by Multiple Intelligence attitude, we also defined as an independent variable. These independent variables came from past research and were evaluated by interviews with five experts to evaluate the independent variable. Then we created a questionnaire to collect data. In the second step, we conducted a survey of 2,000 students from Thai Nichi Institute of Technology. Third, the results of the survey were analyzed to establish the Pattern base for analysis thru data mining.

\subsection{Mapping Module}

A Mapping module (MM) was used to compare data regarding students that login to study via the e-Learning facility. Then, it compares profile with data that is contained in the Pattern-base module. The next process is to analyze the results in order to compare them with the Forecasting module to determine the aptitude of each student.

\subsection{Forecasting Module}

In the Forecasting module (FM) students receive the learning case study content, which is used for predicting the learning type of each student such as analytic case study, introspective case study, or interactive case study. The process begins with matching the learner profile of students with the Pattern-base module to determine which pattern base is matched by Multiple Intelligence. Subsequently, lessons are provided that meet the learner profile of students from the Learning content module. Lastly, data is sent to the Learning portal module, which displays student results.

\subsection{Learning Portal Module}

The Learning portal module (LPM) is responsible for managing learning and instruction. The Learning portal module connects all the modules. 1) The LPM will connect with the Forecasting module and 
Mapping module to send data regarding the learner profile. After students login to the system and are matched with the Pattern-base module, the Forecasting module will send data regarding the learning content back to LPM module for students. 2) The LPM module will then connect with the Adaptive module in order to guide students and adjust according to aptitude.

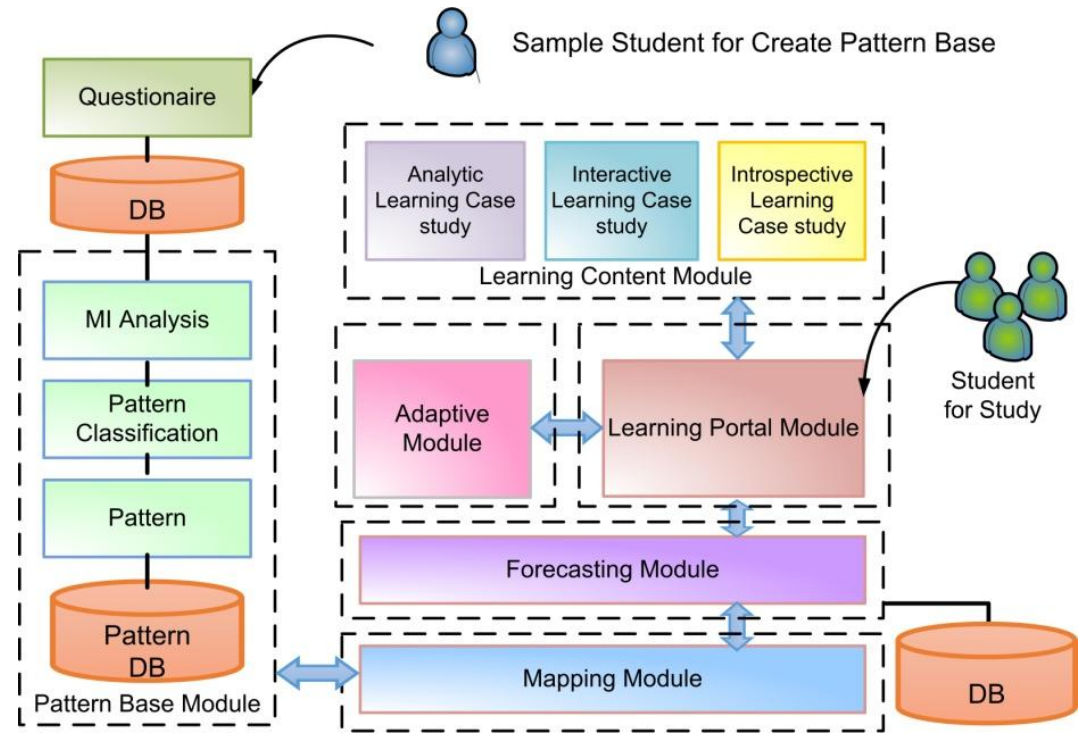

Figure 2. Framework for mobile e-Learning forecasting system

\subsection{Adaptive Module}

The Adaptive module (AM) is responsible for providing appropriate adaptive learning during a course by adjusting the learning path to match each student. Before adjusting a student's learning path, the e-Learning system will test a student in order to check whether it should adapt to an appropriate learning path. For example, for students with the highest scores, the system will adjust the learning path so that it is shorter and progresses faster. For students with lower scores, the system will adjust the learning path to provide additional learning content or review.

\subsection{Learning Content Based On Case Study Module}

Learning content based on the case study module (LCCS) is responsible for collecting content that provides the learning case study content from an analysis of nine Multiple Intelligence types that can be divided into three groups: 1) Analytic content for students who are strongest in analysis and math; 2) Introspective content for students with an aptitude in imagination and arts; and 3) Interactive content for students most comfortable with communication and interaction with others. 


\subsection{Example for Framework}

The process begins when the student logs into the system, which then registers their learner profile, such as, sex, age, year of study and GPA to make a map with the Mapping module of the Pattern-base module. The result of the mapping will demonstrate the aptitude the student has after logging in. The next step moves to the Forecasting module, which is responsible for providing learning content and matching the skills of students based on the Case study module and guides the students via the Learning portal module.

\section{EVALUATION}

The proposed framework was developed using the mobile learning forecasting system and was based on experimental research.

\subsection{Initial Step}

This process begins with a group of normal e-Learning system tests and mobile e-leaning forecasting system tests intending to evaluate the knowledge received from the experiment for students.

Deploys mobile learning forecasting system to a sample of 150 students, consisting of three sample groups to compare average student scores between the normal e-Learning system and the mobile e-learning forecasting system.

Prior to the investigation, there will be guidance for guide sample groups, then they will be tested with 25 questions from science subjects that will be validated for accuracy and appropriateness by an expert in the sciences. Subsequently, the sample group will use the developed mobile e-Learning forecasting system, and another sample group will use studies from the normal e-Learning system.

When the trial finishes, the sample groups will take a test of 25 questions of a science technology test with the same questions from the normal e-Learning system, but switching options.

The results obtained from the sample groups show that the analysis of the distribution $\mathrm{T}$ (t-test) for the sample is not independent of each other. The calculation for the formula of $\mathrm{T}$ is paired (Matched paired $\mathrm{t}$-test) to determine the difference of the test scores of knowledge in the science technology test. This will be compared using the mobile e-Learning forecasting system. The standard of deviation determines the level of satisfaction in using mobile e-Learning forecasting systems. 


\subsection{Evaluation Results}

\subsubsection{Results-1}

Currently, a typical e-Learning system consists of four parts: 1) Learning management system (LMS), 2) Content management system (CMS), 3) Delivery management system (DMS), and 4) Testing management system (TMS). For this e-Learning system, every student in the system will receive the same learning content. The Mobile e-Learning forecasting system represents the design of a new framework that recommends tailored learning content for students and delivers learning content that is matched to the skills of individual students.

The goal of this paper is to design a mobile e-Learning forecasting system. Therefore, the evaluation focuses on results regarding the efficiency of the framework, which is applied to sample student groups. The evaluation is measured via test results about the knowledge of the sample student groups. Results are from the experiment and the science technology test.

Table 1. Comparison of knowledge for sample Group 1

\begin{tabular}{ccccc}
\hline Results & $\bar{\chi}$ & S.D. & $\mathrm{t}$ & $\mathrm{p}$ \\
\hline $\begin{array}{c}\text { Normal e-Learning system } \\
\begin{array}{c}\text { Mobile e-Learning } \\
\text { forecasting system }\end{array}\end{array}$ & 19.02 & 2.130 & $(7.577)$ & .000 \\
\hline
\end{tabular}

Table 2. Comparison of knowledge for sample Group 2

\begin{tabular}{ccccc}
\hline Results & $\bar{\chi}$ & S.D. & $\mathrm{t}$ & $\mathrm{p}$ \\
\hline $\begin{array}{c}\text { Normal e-Learning system } \\
\begin{array}{c}\text { Mobile e-Learning } \\
\text { forecasting system }\end{array}\end{array}$ & 18.96 & 1.927 & $(3.684)$ & .001 \\
\hline
\end{tabular}

Table 3. Comparison of knowledge for sample Group 3

\begin{tabular}{ccccc}
\hline Results & $\bar{\chi}$ & S.D. & $\mathrm{t}$ & $\mathrm{p}$ \\
\hline $\begin{array}{c}\text { Normal e-Learning system } \\
\begin{array}{c}\text { Mobile e-Learning } \\
\text { forecasting system }\end{array}\end{array}$ & 15.180 & 1.924 & $(15.190)$ & .000 \\
\hline
\end{tabular}


Table 1, 2, and 3 show comparisons between the normal e-Learning system and the mobile e-Learning forecasting system, and found that the average score of learning with the mobile e-Learning forecasting system is higher than learning in the normal e-Learning system. Statistical significance was at a 0.05 level (Group 1, $t=7.577, p<0.05$; Group 2, $t=$ 3.684, $p<0.05$; Group 3, $t=15.190, p<0.05)$. These results indicate a satisfactory result among the sample groups for the mobile e-Learning forecasting system.

\subsubsection{Results-2}

This section presents the evaluation of creating a pattern base to guide students by considering the precision percentage based on student ability. One can compare the evaluation of the pattern base by using three methods: 1) J48 algorithm, 2) ID3 algorithm, and 3) Naïve Bayes algorithm. The results of the comparison are shown in Table 4.

Table 4. Comparison of algorithm for pattern base

\begin{tabular}{cc}
\hline Algorithm & \% Prediction \\
\hline 1. J48 Algorithm & 88.286 \\
2. ID3 Algorithm & 78.217 \\
4. Naïve Bayes Algorithm & 71.824 \\
\hline
\end{tabular}

This paper focused on percentage of prediction for each algorithm. The J48 algorithm was found to have the highest percentage of prediction. Percentage of prediction of the $\mathrm{J} 48$ algorithm equaled $88.286 \%$.

\section{CONCLUSION}

The goal of this paper was to design a mobile e-Learning forecasting system based on Multiple Intelligence. The framework consisted of six parts: 1) A Pattern base that differentiates student learning into three groups based on aptitude from Multiple Intelligence; 2) a Forecasting module that introduces students to the content in detail, which is matched with their aptitude, 3) a Learning portal for learning and instruction, 4) an thru an Adaptive module that automatically send instructions to students who need assistance, and 5) learning content that is stored based on content (case study) categorized in terms of Multiple Intelligence types.

The results consisted of two parts. The first part evaluated performance in learning and the average test score with a mobile e-Learning forecasting system. These results were higher than learning in the normal e-Learning 
system. The statistical significance was at a 0.05 level (Group $1, t=7.577, p$ $<0.05$; Group 2, $t=3.684, p<0.05$; Group 3, $t=15.190, p<0.05)$. The second part evaluated precision for predicting student's ability. The J48 algorithm had the highest precision at $88.286 \%$.

This paper presented part of a conceptual framework and the development of a prototype for a mobile e-Learning forecasting system based on case studies using Multiple Intelligence analysis. The next investigation by the authors of this research will focus on precision percentage based on student ability.

\section{REFERENCES}

[1] E-Learning System, Learning management system. Retrieved on April 8, 2015, from http://en.wikipedia.org/wiki/E-learning.

[2] Distance Learning, Component of distance learning. Retrieved on April 18, 2015, from http://en.wikipedia.org/wiki/Distance_education.

[3] Student-centered learning, Type of learning. Retrieved on April 26, 2015, from http://en.wikipedia.org/wiki/ Student- center learning.

[4] P. Polkacha, and M. Tiantong, A conceptual framework of an online project based learning model with intelligence knowledge management and using KWL plus for assessment. In P. Meesad (Ed.), Proceeding of the National Conference on Computing and Information Technology $($ NCCIT)(p734-739). Bangkok: NCCIT Press, 2011.

[5] F. Aruan, S. Prihatmanto, and H. Kuspriyanto, The designing and implementation of a problem based learning in collaborative virtual environments using MMOG Technology. In P. Rusmin (Ed.), Proceeding of the International Conference on System Engineering \& Technology (ICSET) (p1-7). Bandung, Indonesia: IEEE Computer Society, 2012. http://dx.doi.org/10.1109/ICSEngT.2012.6339326.

[6] K. Duangkaew, and S. Tangwannawit, Adaptive presentation of activities learning system based on multiple intelligences. In P. Meesad (Ed.), Proceeding of the National Conference on Computing and Information Technology (NCCIT)(p343-348). Bangkok: NCCIT Press, 2011.

[7] T. Kaewkiriya, N. Utrakrit, S. Tangwannawit, and M. Tiantong, A conceptual framework of synthesize on an adaptive e-learning guidance system base on multiple intelligence, International Journal of Information and Electronic Engineering, 3(6), p622-625, 2013. http://dx.doi.org/10.7763/IJIEE.2013.V3.391.

[8] D. Kelly, and B. Tangney, On the dynamic multiple intelligence informed personalization of the learning environment, Ph.D. dissertation, Dept. Com. Sci., Dublin Univ, Ireland, 2005. 
[9] B. Dara-Abrams, Webtechnologies for multi-intelligent. Retrieved on June 15, 2015, from http://www.brainjolt.com/.

[10] S. Siksen, and M. Tiantong, A conceptual framework of an online project based learning system with a learner guidance system base on multiple intelligence analysis. In P. Meesad (Ed.), Proceeding of the National Conference on Computing and Information Technology $($ NCCIT)(p 699-703). Bangkok: NCCIT Press, 2011.

[11] S. Tangwannawit, Learning activities model in e-learning environment with the development of different multiple intelligences learners, Ph.D. dissertation, Dept. Com. Ed., King Mongkut University of Technology North Bangkok, Bangkok, Thailand, 2010.

[12] S. Tangwannawit, N. Sureerattanan, and M.Tiantong, Multiple intelligences learning activities model in e-learning environment. Special Issue of the International Journal of the Computer, the Internet and Management, 16 (Sp3), p25.1-25.4, 2008.

[13] S. Herman Dwi, The design of adaptive e-learning system based on student's learning styles. International Journal of Computer Science and Information Technologies (IJCSIT), 2(5), p2350-2353, 2011.

[14] O. Pantho, and M. Tiantong, Conceptual framework of synthesize on an adaptive e-learning with e-mentoring system using VARK learning style by data mining methodology. International Journal of Computer Theory and Engineering, (IJCTE), 7(4), p316-319, 2015.

[15] B.S. Gardner, and S.J. Korth, A framework for learning to work in teams. Journal of Education for Business, 74(1), p28-33, 1998. http://dx.doi.org/10.1080/08832329809601657.

[16] A. Thomas, Multiple intelligences in the classroom (3rd ed.). Alexandria, VA: Association for Supervision and Curriculum Development, 2009. 
